\title{
USO DE CULTURAS INICIADORAS PARA A ELABORAÇÃO DE UM EMBUTIDO À BASE DE CARNE DE PATO (Cairina moschata) ${ }^{1}$
}

\author{
Felipe Oliveira CARIONI², Anna Cláudia Simas PORTO², \\ José Carlos Fiad PADILHA ${ }^{3}$, Ernani Sebastião SANT'ANNA ${ }^{2, *}$
}

\begin{abstract}
RESUMO
No Brasil, tanto a criação quanto a comercialização da carne de pato (Cairina moschata) ainda é incipiente, mas devido a sua rusticidade, fácil manejo, e carne apreciada no mercado, entende-se que a obtenção de produtos à base de carne de pato apresentase como uma alternativa rentável na indústria de alimentos. $O$ uso de culturas iniciadoras na elaboração de produtos fermentados é uma prática comum na indústria de produtos cárneos estando diretamente relacionada às características de flavor, textura, cor e vida-de-prateleira do produto final. Avaliou-se o uso de culturas iniciadoras na elaboração de embutido fermentado à base de carne de pato obtida da desossa manual da coxa e sobrecoxa. Uma mistura de culturas iniciadoras de Lactobacillus plantarum BN e Kokuria varians CCT 4492 foi usada para inocular a massa cárnea. Os embutidos foram defumados em câmara para defumação a $23 \pm 1^{\circ} \mathrm{C}$ por aproximadamente 19 horas e curados por 25 dias. A contagem inicial de células viáveis na massa do embutido foi de 6,08 $\mathrm{Log}_{10} \mathrm{UFC} / \mathrm{g}$ e de $6,04 \mathrm{Log}_{10} \mathrm{UFC} / \mathrm{g}$ para bactérias ácido-lácticas e Micrococcacea, respectivamente. Após o segundo dia do processo, bactérias ácido-lácticas apresentaram um crescimento de 0,79 ciclos logarítmicos e no décimo primeiro dia um aumento de 2,58 ciclos logarítmicos. 0 valor médio de acidez, em ácido láctico, no produto final foi de $0,39 \%$ e o valor de $\mathrm{pH}$ de 5,11 . As análises físico-químicas apresentaram-se dentro dos padrões da legislação brasileira. O produto elaborado apresentou perfil sensorial dentro dos padrões aceitáveis de qualidade.
\end{abstract}

Palavras-chave: culturas iniciadoras; fermentação ácido-láctica; embutido; pato.

\section{SUMMARY}

USE OF STARTER CULTURES TO PRODUCE FERMENTED SAUSAGE FROM DUCK MEAT. In Brazil, duck raising (Cairina moschata) and duck meat commercialization are still incipient activities, but due to this animal's rusticity, easiness of management and the marketability of its meat, they may be seen as profitable alternatives in the food industry. The use of starters in the manufacturing of fermented products is a common practice in the meat industry, being directly related to the final product flavor, texture, colour and shelf life. The use of starter cultures to produce fermented sausages with a base of duck meat from the boning of thighs and real thighs was evaluated in this research. A mixture of Lactobacillus plantarum BN and Kokuria varians CCT 4492 starter cultures was used to inoculate the meat mixture. The sausages were smoked in a smoking chamber at $23 \pm 1^{\circ} \mathrm{C}$ for approximately 19 hours and were cured for 25 days. The initial counting of viable cells in the sausage mixture was $6.08 \mathrm{Log}_{10} \mathrm{CFU} / \mathrm{g}$ and $6.04 \mathrm{Log}_{10} \mathrm{CFU} / \mathrm{g}$ for lactic acid bacteria and Micrococcacea, respectively. Acid lactic bacteria displayed a growth of 0.79 logarithm cycles after the second day of processing, and an increase of

\footnotetext{
${ }_{1}^{1}$ Recebido para publicação em 20/04/01. Aceito para publicação em 03/10/01.

${ }_{2}^{2}$ Universidade Federal de Santa Catarina - Departamento de Ciência e Tecnologia de Alimentos. Rodovia Admar Gonzaga, 1346. Florianópolis, SC.E-mail: ernanis@cca.ufsc.br

${ }^{*}$ A quem a correspondência deve ser enviada.
}

2.58 logarithm cycles at the $11^{\text {th }}$ day. The final product acidity average value in lactic acid was $0,39 \%$, and the $\mathrm{pH}$ value, 5.11 . The physico-chemical analyses rested within Brazilian Legal Standards. The final product presented a sensorial profile within acceptable quality standards.

Keywords: starter culture; fermentation lactic-acid; sausage; duck.

\section{1 - INTRODUÇÃO}

A criação do pato (Cairina moschata), também conhecido por pato criolo, ainda é pouco desenvolvida no Brasil, mesmo sendo originário da América do Sul e levado para a Europa no século XVI, onde é bastante desenvolvida, a ponto do consumo per capita na França, em 1988, ser da ordem de 1,2kg [9, 15, 30].

Os embutidos fermentados, como salame e produtos similares, são caracterizados por suas propriedades organolépticas, químicas e microbiológicas [6]. Dois fatores básicos tornam esses produtos diferentes dos demais embutidos: o baixo teor de umidade e a presença de ácido láctico, que confere um sabor característico [10, 29].

Segundo YAMADA [31], o método tradicional de fabricação do salame resume-se na moagem da carne, pré-cura, condimentação, embutimento e maturação até atingir 60 a $80 \%$ de seu peso original. Os embutidos secos não são cozidos e a maturação é feita a temperaturas baixas $\left(5-25^{\circ} \mathrm{C}\right)$. A formação da cor, aromatização, aderência das partículas e secagem são as transformações mais acentuadas que ocorrem durante a maturação (tempo de cura). O salame curado corretamente torna-se um produto estável por evitar a multiplicação de microrganismos indesejáveis [3].

As culturas iniciadoras utilizadas em salames consistem de um ou dois microrganismos. Um microrganismo acidificante - como lactobacilos ou pediococos - que tem a função de estabilizar o produto biologicamente, e um microrganismo nitrato-redutor, se existir nitrato na formulação. Estes microrganismos nitratoredutores são comumente micrococos ou estafilococos coagulase negativa [23].

A principal função das bactérias lácticas na fermentação de carnes é a rápida produção de ácido láctico, o que provoca a redução do $\mathrm{pH}$ inibindo a ação de microrganismos patogênicos [18], e aumentando a vidade-prateleira do produto processado [16]; outras funções destas bactérias são a produção de flavor diferenciado e a desnaturação das proteínas, resultando na expulsão da água que é a principal responsável pela textura [28]. Alguns autores têm demonstrado que a produção de ácido láctico e conseqüente queda do $\mathrm{pH}$ 
é o fator mais importante na inibição do crescimento de Clostridium botulinum em embutidos fermentados [8].

Em produtos fermentados da Europa, especialmente nos países do sul do Mediterrâneo, os organismos mais importantes em fermentações naturais e também os mais usados como culturas iniciadoras para carnes fermentadas são Lactobacillus sakei, Lactobacillus curvatus e Lactobacillus plantarum [16, 27].

Segundo LÜCKE [22], as bactérias nitrato-redutoras, dos gêneros Staphylococcus e Micrococcus são usadas em combinação com bactérias ácido-lácticas por contribuirem para o flavor, atividade lipolítica, redução de nitratos e produção de catalase. Outra função importante das bactérias nitrato-redutoras em produtos cárneos curados é proteger as gorduras do oxigênio do ar, evitando a rancificação, que constitui um problema maior nos produtos cárneos crus do que nos cozidos [22]. Kokuria varians possui características como rapidez na redução do nitrato, desenvolvimento de cor e flavor no produto, bem como na inibição do desenvolvimento de microrganismos indesejáveis [21].

Dentre os diversos cortes oriundos do abate dos patos, o mais apreciado e mais comercializado é o peito, alcançando preços significativos no mercado consumidor, enquanto outros cortes como coxa e sobrecoxa não são satisfatoriamente apreciados. Em função desta realidade, o objetivo do presente trabalho foi procurar desenvolver um produto diferenciado, não disponível no mercado nacional, que utilizasse estas matériasprimas, bem como o excesso de gordura oriundo dos diversos cortes.

\section{2 - MATERIAIS E MÉTODOS}

\section{1 - Obtenção da matéria-prima}

Matrizes de pato (Cairina moschata) foram adquiridas no comércio local, para procriação e obtenção da matéria-prima. Os ovos fecundados foram incubados a $37,6^{\circ} \mathrm{C}$ e o nascimento dos animais ocorreu após aproximadamente 35 dias de incubação. A idade do abate foi de 84 dias para os machos e 70 dias para as fêmeas de acordo com SAUVEUR [25]. Após o abate, as carnes foram congeladas $\mathrm{a}-18^{\circ} \mathrm{C}$.

\section{2 - Rendimento dos cortes}

O rendimento dos cortes (coxa e sobrecoxa) foi calculado em relação ao peso do animal vivo.

\section{3 - Culturas iniciadoras}

Foram utilizados Lactobacillus plantarum BN e Kokuria varians CCT 4492 cultivados no Laboratório de Biotecnologia Alimentar do Centro de Ciências Agrárias da Universidade Federal de Santa Catarina. Lactobacillus plantarum BN foi cultivado em caldo MRS (De Man, Rogosa e Sharpe), por 48 horas a $30^{\circ} \mathrm{C}$. Kokuria varians CCT 4492 foi cultivado em caldo $\mathrm{BHI}$ (Brain Heart Infusion) por 24 horas a $35^{\circ} \mathrm{C}$. Foi determinada a concentração do inóculo $\left(10^{6} \mathrm{UFC} / \mathrm{mL}\right)$, utilizando-se o mé- todo de ensaio espectrofotométrico [19], e a viabilidade das células através de contagem em placas de Petri, em profundidade, utilizando-se ágar MRS, após 48 horas a $30^{\circ} \mathrm{C}$, para Lactobacillus plantarum $\mathrm{BN}$ e ágar $\mathrm{BHI}$, após 24 horas a $35^{\circ} \mathrm{C}$, para Kokuria varians CCT 4492.

\section{4 - Elaboração do embutido}

Todos os ingredientes foram pesados separadamente. O embutido foi elaborado de acordo com a seguinte formulação: carne de coxa e sobrecoxa de pato desossada $(84,74 \%)$; gordura de pato $(8,50 \%)$; proteína de soja isolada $(1,90 \%)$; cloreto de sódio $(1,90 \%)$; alho $(0,10 \%)$; vinho $(1,00 \%)$; pimenta-do-reino $(0,07 \%)$; nozmoscada $(0,04 \%)$; açúcar $(0,50 \%)$; sais de cura (nitrato e nitrito) $(1,00 \%)$ e eritorbato de sódio $(0,25 \%)$. A carne da coxa e sobrecoxa de pato foi moída em cutter. Após a moagem da carne adicionaram-se 106-107 UFC/g de massa, do cultivo iniciador (Lactobacillus plantarum BN e Kokuria varians), açúcar, proteína isolada de soja, alho e vinho. A massa foi homogeneizada por 5 minutos em misturador apropriado (Sopama) e acrescentados gordura de pato, cloreto de sódio e sal de cura. Após a adição de todos os ingredientes, a massa foi homogeneizada por 10 minutos. O embutimento da massa foi em tripa de colágeno $(50 \mathrm{~mm})$ para salame (Colfan) em embutideira manual. As peças foram pesadas individualmente e, em seguida, defumadas em uma câmara de 1 metro de largura por 1 metro de comprimento e 3 metros de altura. A temperatura de defumação foi $23^{\circ} \mathrm{C} \pm 1^{\circ} \mathrm{C}$ por aproximadamente 19 horas. Posteriormente, as peças foram pesadas para o cálculo da quebra de peso durante a defumação. Os embutidos defumados foram maturados durante 25 dias sob os seguintes parâmetros: temperatura de $17^{\circ} \mathrm{C}$, umidade de $70-80 \%$ e ventilação de $0,5 \mathrm{~m} / \mathrm{s}$ nos 7 primeiros dias; do oitavo ao $14^{\circ}$ dia a temperatura de maturação foi $16^{\circ} \mathrm{C}$, umidade de $75-80 \%$ e ventilação de 0,5 . Do décimo quinto ao vigésimo quinto dia a temperatura foi de $15^{\circ} \mathrm{C}$, umidade de $76-82 \%$ e ventilação de $0,5 \mathrm{~m} / \mathrm{s}$.

\section{5 - Análises físico-químicas}

As análises físico-químicas de controle foram realizadas tanto na massa como no produto curado, determinadas de acordo com a AOAC [2]: acidez, em ácido láctico (técnica $n^{\circ} 920.124$ ); nitrito residual (técnica $n^{\circ}$ 973.31); nitrato (técnica $n^{\circ}$ 973.31); umidade (técnica $\mathrm{n}^{\circ} 930.15$ ); proteína bruta (técnica $\mathrm{n}^{\circ} 981.010$ ); lipídios (técnica $n^{\circ}$ 991.36) e pH utilizando-se potenciômetro.

\section{6 - Análises microbiológicas}

As determinações microbiológicas foram feitas semanalmente durante o processo fermentativo e após o término da fermentação. As contagens de Lactobacillus plantarum e Kokuria varians foram realizadas no $2^{\circ}, 11^{\circ}$, $18^{\circ}$ e $25^{\circ}$ dias. As contagens de aeróbios totais, enterobactérias, determinação das bactérias ácidolácticas, bactérias nitrato-redutoras, clostrídios sulfito redutores $\left(\mathrm{a} 44^{\circ} \mathrm{C}\right)$, Salmonella e Staphylococcus aureus foram realizadas de acordo com o American Public Health 
Association [1]. As amostras foram retiradas na parte central e nas duas extremidades do embutido.

\section{7 - Análise sensorial}

A avaliação sensorial do embutido à base de carne de pato foi feita através da aplicação do teste de perfil de características, com 3 repetições, por equipe de julgadores treinados do Departamento de Ciência e Tecnologia de Alimentos do Centro de Ciências Agrárias da Universidade Federal de Santa Catarina. Os julgadores receberam orientação do método e procedimento da prova, objetivando o preenchimento correto das fichas de avaliação, e evitando possíveis erros. Avaliaram-se os atributos de aparência, cor, odor e consistência, através de uma escala de valores, cuja pontuação foi de 1 (um) a 5 (cinco), sendo 1 (um) péssimo, 3 (três) bom e 5 (ótimo) [27].

\section{3 - RESULTADOS E DISCUSSÃO}

\section{1 - Rendimento dos cortes}

O rendimento dos cortes em relação ao peso vivo foi de $19,7 \%$ para os animais machos e de $17,8 \%$ para as fêmeas. Comparando os resultados obtidos com os dados de GRIMAUD FRÈRES [13] (17,01\% para machos e $15,67 \%$ para fêmeas), observou-se um maior rendimento que pode ser atribuído à genética bem como à manipulação dos cortes. O rendimento da desossa da coxa e sobrecoxa (sem pele) para os animais machos $(52,8 \%)$ e fêmeas $(52,2 \%)$ não apresentou uma diferença significativa entre os animais pesquisados.

\section{2 - Análises físico-químicas}

A formulação utilizada mostrou-se adequada para a elaboração do embutido à base de carne de pato, obtendo-se um produto final com características dentro dos parâmetros físico-químicos e microbiológicos esperados. A Figura 1 apresenta os valores médios de $\mathrm{pH}$ durante a maturação do embutido. Os valores obtidos podem ser considerados normais para este tipo de produto. $\mathrm{O} \mathrm{pH}$ final alcançado foi de 5,11 .

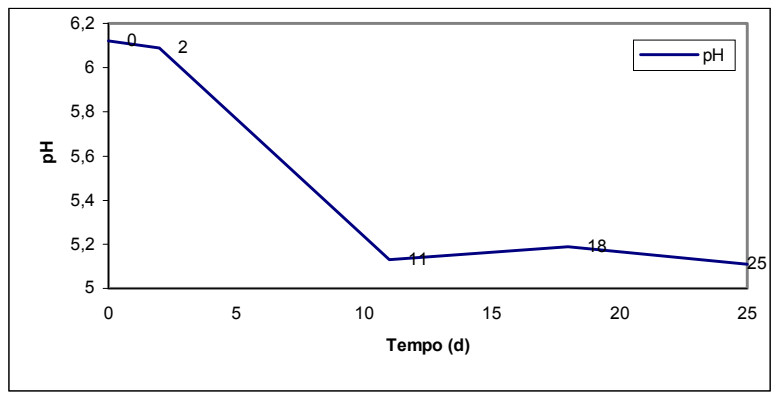

Parâmetros de maturação:

de $0-7$ dias: temperatura: $17^{\circ} \mathrm{C}$, umidade relativa: $70-80 \%$, fluxo de ar: $0,5 \mathrm{~m} / \mathrm{s}$.

de $16-25$ dias: to $0,5 \mathrm{~m} / \mathrm{s}$.

FIGURA 1. Valores de pH durante a maturação de embutido à base de carne de pato.
IBAÑEZ et al. [17], avaliando os efeitos da adição de cloreto de sódio e cloreto de potássio em salames, obtiveram $\mathrm{pH}$ final entre 4,99 e 5,06. Um leve aumento do valor de $\mathrm{pH}$ foi observado no décimo oitavo dia de maturação, que pode ser resultado da produção de amônia ou outros compostos básicos originados da atividade proteolítica [6].O valor médio final de acidez, em ácido láctico no produto elaborado (Figura 2), foi de 0,39\%. GOMIDE et al. [12], avaliando os efeitos de carne de frango mecanicamente separada em embutidos fermentados, obtiveram valores aproximados. O efeito do tempo na produção/concentração de ácido láctico devese ao crescimento das culturas lácticas e à secagem dos embutidos [13].

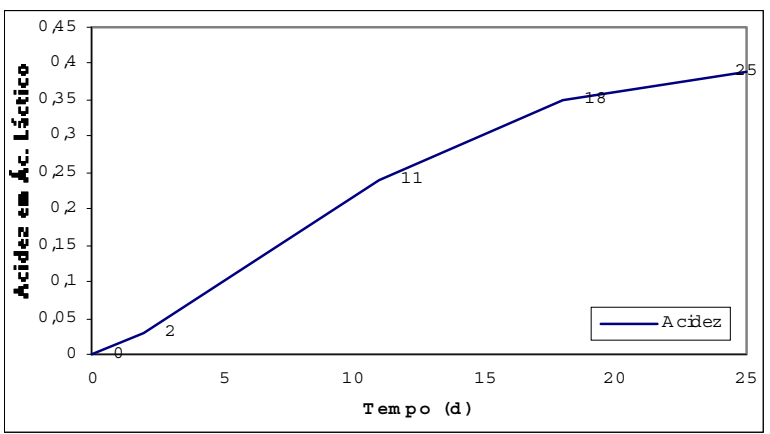

FIGURA 2. Valores de acidez durante a maturação de embutido à base de carne de pato.

Os ácidos produzidos por bactérias ácido-lácticas diminuem o pH e contribuem para a conservação do produto cárneo fermentado. O ácido láctico confere um flavor ácido e desnatura a proteína, resultando na textura associada a salames fermentados [26]. Um dos mais importantes constituintes dos salames, tanto no aspecto nutricional como tecnológico, são as proteínas, entre suas propriedades estão a solubilidade, viscosidade, ligação água-gordura e emulsificação [17]. A análise da fração protéica, mostrou um valor médio de 18,71\% na massa do embutido e $23,42 \%$ no embutido maturado. Valor similar ao embutido maturado foi encontrado por CAVENAGHI, OLIVEIRA [7], embora avaliando as características físico-químicas e sensoriais do salame tipo italiano fabricado no Brasil.

O conteúdo de umidade inicial médio foi de $65,78 \%$. Após 25 dias de maturação, o produto final apresentou conteúdo de umidade médio de 38,91\%. Resultado similar foi observado por KENNEALLY LEUSCHNER, ARENDT [20] (50-54\% e 31-32\%, respectivamente) em salames inoculados com culturas iniciadoras (bactérias ácido-lácticas e nitrato-redutoras).

\section{3 - Análises microbiológicas}

A queda do $\mathrm{pH}$ e o aumento da acidez estão relacionados com o crescimento de Lactobacillus plantarum BN (Figura 3), devido ao ácido láctico produzido por esta bactéria. A concentração média inicial de células viáveis de bactérias ácido-lácticas foi de 6,08 $\log _{10} \mathrm{UFC} / \mathrm{g}$, 
com um aumento de 0,79 ciclos logarítimicos após dois dias de produção. No décimo primeiro dia, o embutido elaborado apresentou um aumento de 2,58 ciclos logarítimicos. No final do processo, o valor médio final de células viáveis de bactérias lácticas foi de $8,11 \log _{10}$ UFC/g.

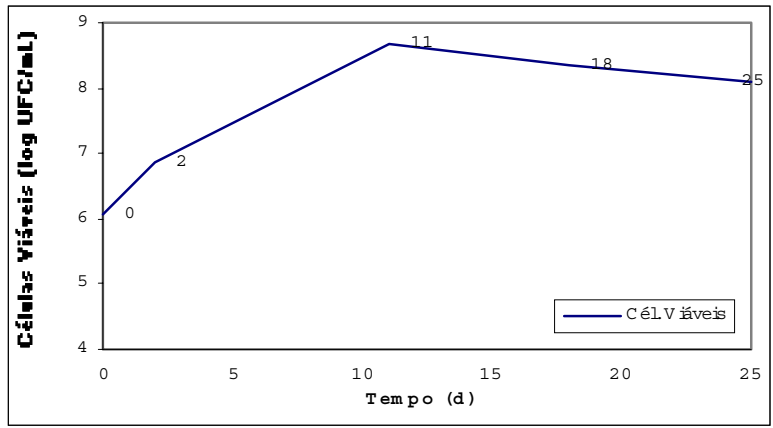

FIGURA 3. Curva de crescimento de Lactobacillus plantarum $\mathrm{BN}$ durante a maturação de embutido à base de carne de pato.

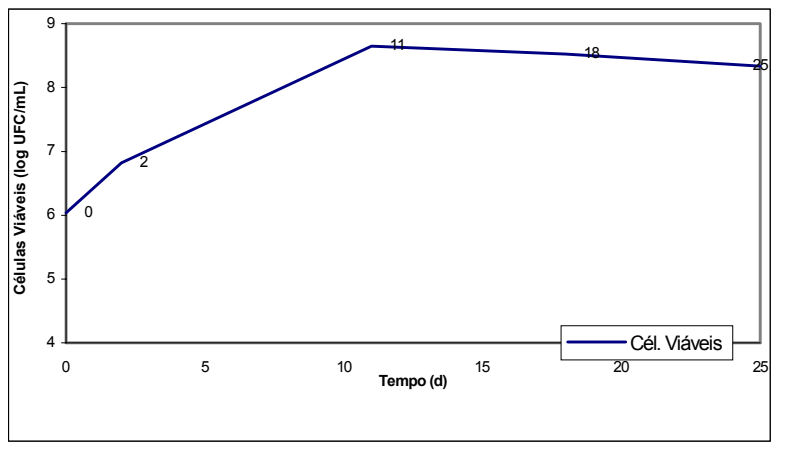

FIGURA 4. Curva de crescimento de Micrococcacea durante a maturação de embutido à base de carne de pato.

A Figura 4 mostra o valor médio de células viáveis de Micrococcacea. O número médio inicial de células viáveis foi de $6,04 \log _{10} \mathrm{UFC} / \mathrm{g}$ e apresentou um crescimento de 0,79 ciclos logarítimicos, no segundo dia do processo.

No décimo primeiro dia, o número de células viáveis destas bactérias foi $8,65 \log _{10} \mathrm{UFC} / \mathrm{g}$, sendo que no décimo oitavo dia observou-se um descrécimo de 0,12 ciclos logarítmicos. O número médio final de células viáveis foi de $8,34 \log _{10} \mathrm{UFC} / \mathrm{g}$. Este comportamento foi observado também por GARCIA et al. [11] e KENNEALLY, LEUSCHNER, ARENDT [20].

Micrococcacea estão relacionadas com a redução de nitrato a nitrito. A análise laboratorial do embutido apresentou teores médios de nitrito e nitrato de $1,70 \mathrm{mg} / 100 \mathrm{~g}$ e $15,51 \mathrm{mg} / 100 \mathrm{~g}$, respectivamente. Esses valores estão de acordo com a Portaria $n^{\circ} 1.004$ de 11 de dezembro de 1998 do Departamento de Inspeção de Produtos de Origem Animal do Ministério da Agricultura e do Abastecimento, na qual atribui valores máximos no salame de $15,0 \mathrm{mg} / 100 \mathrm{~g}$ de nitrito e $30,0 \mathrm{mg} / 100 \mathrm{~g}$ de nitrato [4].
Enterobacteriaceae são contaminantes comuns da carne e, além disso, podem estar presentes nos substratos de fermentação, sendo que o número desses microrganismos presentes depende da contagem inicial na matéria-prima, do tipo de embutido e do estágio do processo de maturação. Sob a presença de sais de cura e culturas iniciadoras, estes números declinam consideravelmente, e isto é considerado essencial no controle de patógenos em alimentos como Salmonella, Shigella ou cepas de Escherichia coli [14].

A qualidade microbiológica do embutido elaborado pode ser observada na Tabela 1. Observou-se que o produto estava dentro dos padrões estabelecidos pela Resolução RDC n 12 de 2 de janeiro de 2001 da Agência Nacional de Vigilância Sanitária, que estabelece os seguintes valores máximos para produtos cárneos maturados: ausência de Salmonella sp em $25 \mathrm{~g}$ de amostra, $10^{3} \mathrm{NMP} / \mathrm{g}$ de amostra para Coliformes a $45^{\circ} \mathrm{C}$ e 5 X $10^{3} \mathrm{UFC} / \mathrm{g}$ de amostra de Staphylococcus coagulase positiva [5].

TABELA 1. Resultados da análise microbiológica no embutido à base de carne de pato (Cairina moschata) em 25 dias.

\begin{tabular}{lc}
\hline Microrganismos & \\
\hline Salmonella sp. (ausência em $25 \mathrm{~g})$ & Ausente \\
Clostridium sulfito redutor $\left(\log _{10} \mathrm{UFC} / \mathrm{g}\right)$ & nd \\
Staphylococcus coagulase $(+)\left(\log _{10} \mathrm{UFC} / \mathrm{g}\right)$ & nd \\
Coliformes Totais $(\mathrm{NMP} / \mathrm{g})$ & $<3$ \\
\hline
\end{tabular}

nd: não detectado

\section{4 - Analise sensorial}

Os resultados do perfil de características estão representados graficamente na Figura 5. Analisando-se a figura, observa-se que o embutido à base de carne de pato apresentou-se dentro dos padrões aceitáveis de qualidade, com médias maiores que 3 (três) e menores que 4 (quatro) [24]. As médias atribuídas foram de 3,1 para o atributo aparência; 3,17 para cor; 3,32 para o sabor; 3,85 para o odor e, 3,37 para o atributo textura.

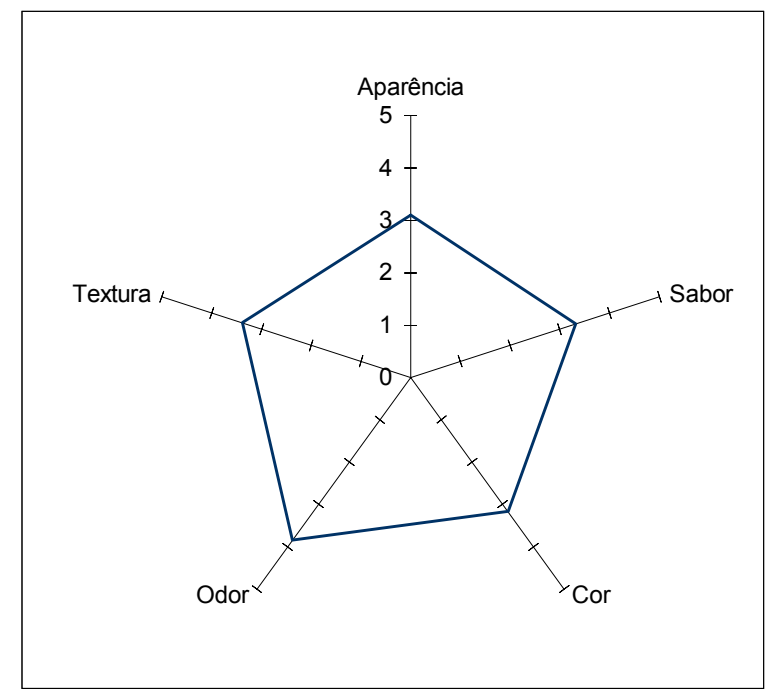

FIGURA 5. Perfil de características do embutido à base de carne de pato. 
Apesar do produto ter apresentado um perfil sensorial dentro dos padrões aceitáveis de qualidade, observou-se que a textura, aparência e sabor do produto elaborado apresentaram alguns aspectos negativos, como aparência de massa não homogênea e oleosidade, leve sabor residual e textura não firme. Tais aspectos podem estar relacionados com as matérias-primas utilizadas (carne e gordura de pato), uma vez que os atributos sensoriais derivam principalmente destas matéria-primas. O sabor residual pode estar relacionado com a concentração de proteína de soja utilizada $(2 \%)$, embora em embutidos à base de carne suína ou bovina e nesta concentração não se tenha nenhuma referência de tal efeito. Já em relação ao atributo cor, a matériaprima pode ter influenciado na cor final do produto, uma vez que tal observação foi citada e comparada pelos julgadores, com salames de carne suína/bovina.

\section{4 - CONCLUSÕES}

A formulação utilizada na elaboração do embutido à base de carne de pato mostrou-se adequada, podendo ser melhorada, obtendo-se um produto final com características dentro dos parâmetros físico-químicos e microbiológicos esperados.

O embutido à base de carne de pato apresentou perfil sensorial dentro dos padrões aceitáveis de qualidade.

Sobre os parâmetros físico-químicos, microbiológicos e sensoriais é viável a produção de um embutido fermentado à base de carne da desossa da coxa e sobrecoxa do pato (Cairina moschata).

\section{5 - REFERÊNCIAS BIBLIOGRÁFICAS}

[1] AMERICAN PUBLIC HEALTH ASSOCIATION. Compendium of Methods for the Microbiological Examination of Foods. In: VANDERZANT, C., SPLITTSTOESSER, Don F. (ed.), 3.ed, 1219p., 1992.

[2] ASSOCIATION OF OFFICIAL ANALYTICAL CHEMISTS. Official methods of analysis. Med, Virginia: Association of Official Analytical Chemists, 1988.

[3] BALDINI, P; FARINA, G; PALMIA, F. Studi sulle tecniche di preparazione e stagionatura dei salami crudi: impiego di acido acetico e di nitrito sodico. Industria conserve, v.56, n. 3, p. 204-212, 1981.

[4] BRASIL. Ministério da Agricultura e do Abastecimento. Departamento de Inspeção de Produtos de Origem Animal. Circular n. 128/99/DCI/DIPOA. Brasília, 1999.

[5] BRASII. Ministério da Saúde. Agência Nacional de Vigilância Sanitária - ANVISA, RDC n 12 de 2 de janeiro de 2001. Padrões Microbiológicos. Brasília, 2001

[6] BUCKENHÜSKES, H.J. Seletion criteria for lactic acid bacteria to be used as starter cultures for various food commodities. FEMS Microbiology Reviews, v. 12, p. 253-277, 1993.

[7] CAVENAGHI, A.D.; OLIVEIRA, M.N. Influência de algumas características físico-químicas e sensoriais na qualidade de salame tipo italiano fabricado no Brasil. Revista Nacional da Carne, v. 23, p. 43-46, 1999.

[8] CHRISTIANSEN, L.N. Effect of sodium nitrite and nitrate on C. botulinum. Growth and toxin production in summer style sausage. Journal of Food Science, v. 40, p. 488493, 1975

[9] FABICHACK, J. Patos e Marrecos. São Paulo: Nobel, 1988, 56 p.
[10] GALLI, F. Os embutidos - como fabricá-los. Revista Nacional da Carne, n. 194, abr., p. 16-28, 1993.

[11] GARCIA, M.C., SELGAS, D.M., FERNANDEZ, M., ORDOÑEZ, J.A. Microorganisms and lipolysis in the ripening of dry fermented sausages. International Journal of Food Science and Technology, v. 27, p. 675-682, 1992.

[12] GOMIDE, L.A.M.; GARCIA, A.M.; PEREIRA, A.S.O.; MENDONÇA, R.C.S. Avaliação físico-química e microbiológica da adição de carne de frango mecanicamente separada em embutido fermentado. Ciênc. e Tecnol. de Aliment., v. 17, n. 2 , p. 125-131, 1997.

[13] GRIMAUD FRERES. Informe Técnico. Roussay, França. 1999.

[14] HAMMES, W.P.; KNAUF, H.J. Starters in the processing of meat products. Meat Science, v. 36, p.155-168, 1994.

[15] HOLLINGSWORTH, P. Global opportunities. Food Technology, v. 48, n. 3, p. 65-68, 1994.

[16] HUGAS, M. Bacteriocinogenic Lactic Acid Bacteria for the Biopreservation of Meat and Meat Products. Meat Science, Oxford, v. 49, p. 139-150, 1998.

[17] IBAÑEZ, C.; QUINTANILLA, C.; CID, C.; et al. Dry fermented sausages elaborated with Lactobacillus plantarumStaphylococcus carnosus.2. Effect of partial replacement of $\mathrm{NaCl}$ with $\mathrm{KCl}$ on the Proteolytic and insolubilization processes. Meat Science. Oxford, v. 46, n. 3, p. 277-284, 1997.

[18] INCZE, K. Dry Fermented Sausages, Meat Science, Oxford, v. 49, p. 169-177, 1998.

[19] KANASAKI, M; BREHENY, S; HILLIER, A.J.; JAGO, G.R. Effects of temperature on the growth and acid production of lactic acid bacteria. Australian Journal of Dairy Technology, Australia, v. 30, n. 4, p. 141-144, 1975.

[20] KENNEALLY, P.M.; LEUSCHNER, R.G.; ARENDT, E.K. Evaluation of the lipolytic of starter cultures for meat fermentation purposes. Journal of Applied Microbiology, Oxford, v. 84, n. 5, p. 839-846, 1998.

[21] LUCKE, F.K. Fermented sausages. In: WOOD, B.J.B.(ed.). Microbiology of fermented foods. New York: Elsevier applied science, 1985.2 v. il.

[22] LUCKE, F.K. Microbiological process in the manufacture of dry sausage and raw ham. Fleischuwirtschaft, Frankfurt, v. 66, n. 10, p. 1505-1509, 1986.

[23] MARCHESINI, B. BRUTTIN, A., ROMALLES, N., MOCTON, R.S., STUCCHI, C. SOZZI, T. Microbiological events during commercial meat fermentation. Journal Applied Bacteriology, Oxford, v. 73, p. 203-209, 1992.

[24] McDERMOTT, B.J. Identifying consumers and test subjects. Food Technology, v. 44, n. 11, p. 154-158, 1990.

[25] SAUVEUR, B. Origines et performances comparées du canard de Barbarie et du canard commun de race Pékin. In: SAUVER, H.B., CARVILLE, A.(ed.). Le Canard de Barbarie. Paris:INRA, p. 5-9, 1990.

[26] SMITH, J.L., PALUMBO, S.A. Microorganisms as Food Additives. Journal of Food Protection, v. 44, p. 936955, Dec. 1981.

[27] TEIXEIRA, E; MEINERT, E.M.; BARBETTA, P.A. Análise sensorial de Alimentos. Florianópolis: Ed. da UFSC, 1987. 180p. il.

[28] VERSCOVO, M.; TORRIANI, S.; DELLAGLIO, F.; BOTTAZZI, V. Basic characteristics, ecology and application of Lactobacillus plantarum: a review. Annimal Microbiology Enzimology., v. 43, p. 261-284, 1993.

[29] VIGNOLO, G.M. Use of Bacterial Cultures in the Ripening of Fermented Sausages. Journal of Food Protection, v. 52, p. 787-791, nov.1989.

[30] VILLATE, D. Manuel Pratique Des Maladies Des Palmipedes. Paris: France Agricole, 1989, 177p.

[31] YAMADA, E.A. A produção de salames. Revista Nacional da Carne, n. 220, jan., p. 72-75, 1995. 